\section{Palaeontological and molecular views of panda phylogeny}

THE recent valuable contribution to panda phylogeny by O'Brien et al. ${ }^{1}$ corroborates quite well the existing palaeontological information.

Ailuropoda, the giant panda, has distinctive teeth and skull. It was a major and widespread element in the early Pleistocene fauna of southeast Asia, and its ancestors occurred much farther afield Thenius $^{2,3}$ has shown that it originated from the poorly known late Miocene bear Agriarctos, which has not yet been found outside Europe. Agriarctos had a separate origin from the modern bears in the earlier Miocene genus Ursavus. Thenius put the divergence time of Ailuropoda between 15 and $20 \mathrm{Myr}$, as does an average of the molecular chronologies of O'Brien et al., although neither approach can as yet be very accurate here.

Thenius $^{2}$ and others ${ }^{4,5}$ have also contributed to the fossil history of Ailurus, the lesser panda. The Holarctic Pliocene genus Parailurus is a collateral relative, and both came from the Eurasian genus Sivanasua of the early and middle Miocene. Sivanasua is a good if primitive procyonid, branching between the divergence of modern mustelids and procyonids. The Procyonidae would perhaps be polyphyletic if the ancestral musteloids are excluded from this family; even Ailurus retains some basicranial and other features changed in other modern procy. onids but also retained by bears. The relevant late Eocene and Oligocene genera of the Amphicyonidae, in a broad sense, have not yet been studied adequately by current methods and so the time of divergence of Procyonidae and Ursidae within that interval is unclear. I agree ${ }^{1,6}$ that subfamilial distinction of each panda, with its relatives, from the rest of the members of their respective families is appropriate.

Leigh M. VAN Valen

Biology Department (Whitman),

University of Chicago,

915 East 57th Street,

Chicago, Illinois 60637 USA

1. O'Brien, S. J., Nash, W. G., Wildt, D. E., Bush, M. E. \& Benveniste, R. E. Nature 317, 140-144 (1985)

2. Thenius, E. Z. Säugetierk 44, 286-305 (1979).

3. Thenius, E. Z. Geol. Wiss. 10, 1029-1042 (1982)

4. Pilgrim, G. E. Palaeont. Indica, New Ser. 18, 1-232 (1932)

5. Tedford, R. H. \& Gustafson, E. P. Nature 265, 621-623 (1977)

6. Stains, H. J. in Orders and Families of Recent Mammals of the World (eds Anderson, S. \& Jones, J. K., Jr) 491-521 (Wiley, New York, 1984).

O'BRIEN ET AL. REPLY-We are pleased indeed to have our molecular phylogeny corroborated by the palaeontological record as pointed out by such eminent authorities as Professors Kurtén (Nature 318,$487 ; 1985$ ) and Van Valen (above). It is reassuring to find that the molecular

topology we have constructed can be consistently interpreted by the limited, but informative fossil record of the ursid and procyonid progenitors. Because of inherent limitations in any individual approach, synthetic analysis of multiple methods of phylogenic inference is particularly important in the resolution of evolutionary relationship. Derivation of a consensus molecular / cytogenetic / palaeontological story for the pandas is a persuasive example of how a long debated puzzle can be correctly resolved and the bases for the controversies themselves ultimately interpreted. I hope that our agreement concerning the assignment of subfamily status of the giant panda in the Ursidae will be adopted by students of mammalian taxonomy.

\section{STEPHEN J. O'BRIEN* \\ WILLIAM G. NASH* \\ RAOUL E. BENVENISTE* \\ DAVID E. WILDT $\dagger$ \\ MITCH E. BuSH ${ }^{\dagger}$}

* Laboratory of Viral Carcinogenesis, National Cancer Institute, Frederick, Maryland 21701, USA $\dagger$ Department of Animal Health, National Zoological Park, 3000 Connecticut Avenue, Washington, DC, USA

\section{Oncofetal antigens}

IN the review article by Feizi ${ }^{1}$ the term 'oncofetal' antigen (OFA) is used to describe those determinants that are expressed in fetal, tumour and specific adult tissues in modified or quantitatively varying levels. This misnomer has become a common problem to many tumour biologists. Many view the oncofetal antigen prototype as carcinoembryonic antigen (CEA) or $\alpha$-fetoprotein (AFP). This is incorrect. Although these antigens were first considered as examples of reexpressed fetal gene products that were proposed to be tumour-specific in adults, the subsequent discovery of their presence in diseased, non-tumour tissue as well as some limited expression in normal adult tissues should have caused them to be classified as differentiation antigens. The purpose of this response is to implore tumour biologists to use the correct nomeclature.

For clarification, the original definition of the term oncofetal antigen, put into contemporary use in the early 1970 s by Alexander, Medawar and my group after CEA and AFP were found not to be tumour-specific markers, was as follows: OFAs are antigen substances expressed exclusively as phase-specific autoantigens in developing embryo or fetal tissues of metazoans and in their tumours ${ }^{2}$. The important criteria that must be fulfilled if an epitope is to be classed as an OFA are:
(1) The expression of the OFA epitope must be restricted to embryo, fetal and tumour tissue and not be found in any adult, normal tissue; (2) The OFA epitope must be autoantigenic in the pregnant female carrying the embryo or fetus and in the tumour-bearing host.

Epitopes not fulfilling these criteria are differentiation antigens if they are transiently or permanently expressed in adult as well as fetal and/or tumour tissue with or without autoimmunogenicity and reflect various stages of cellular differentiation.

Adherence to this simple set of distinguishing criteria in naming tissue-associated antigens will greatly avoid confusion. Examples of possible true OFAs are the polypeptides of relative molecular mass 44,000 and 200,000 recently described in fetal and tumour cells of rodents and $\operatorname{man}^{3}$ and possibly certain phosphorylated or truncated forms of the protein p53.

I further recommend that antigens similar to those described in ref. 1 be designated embryo/fetal/tumour (EFT) differentiation antigens. Such EFT differentiation determinants would conventionally be detected with xenogeneically derived antibody or monoclonal antibody as epitopes that appear in greater concentration in embryo-fetal and tumour tissue than in normal, fully differentiated, adult tissue. The term oncodevelopmental antigen should be discontinued as it has never been formally defined.

JOSEPH H. COGGIN JR

Department of Microbiology and Immunology,

University of South Alabama

College of Medicine, Mobile,

Alabama 36688, USA

1. Feizi, T. Nature 314, 53-57 (1985).

2. Ambrose, K., Andersson, N. \& Coggin, J. Nature 233, 194-195 (1971).

3. Payne, W. \& Coggin, J. H. J. natn. Cancer Inst. 75, 527-544 (1985).

FEIzI REPLIES-My $\operatorname{article}^{1}$ was based on information available on the precise antigenic determinants expressed on the surface of cells and recognized by monoclonal antibodies as tumour-associated, developmentally regulated or other differentiation antigens. At the time (and to my knowledge even now) the only characterized determinants have been carbohydrate sequences. Clearly it will be desirable to classify properly the various antigens in their biological context when their structures and distributions in diverse tissues have been thoroughly evaluated. Nomenclature can then be rationalized.

TEN FEIZI

Applied Immunochemistry Research Group, Clinical Research Centre, Watford Road, Harrow, Middlesex HA1 3UJ, UK 